\section{Marka İmajının Satın Alma Niyetine Etkisinde Müşteri Tatmininin Aracı Rolü: Üniversite Öğrencileri Üzerine Bir Araştırma}

\section{Zafer Sayan $^{\mathrm{a}}$}

Öz: Global dünyada teknolojik gelişmelerin etkisiyle akıllı telefon markaları işlevsel özelliklerini kullanarak farklılaşmaktadır. Müşteriler ise satın alma niyetlerine göre kendilerine yakın buldukları markaları seçmektedirler. Müşterilerin satın alma niyetini açıklamaya yönelik daha önceki araştırmalar çoğunlukla psikolojik, demografik ve algısal faktörler üzerinden gerçekleştirilmiştir. Müşteriler satın alma niyetinde oldukları mal ve hizmetleri marka imajı üzerinden ele aldıklarından, işletmelerin müşteri tatmini esaslı ilişkiyi sürdürmeleri önemlidir. Bu çalışmanın amacı, üniversite öğrencilerinin akılı telefon kullanımı özelinde, marka imajı değişkeninin satın alma niyeti üzerindeki etkisinin, müşteri tatmininin aracı değişken rolü üzerinden incelenmesidir. Araştırmada, istanbul'daki bir vakıf üniversitesinden kolayda örneklem metoduyla seçilen 352 öğrenciden anket verisi elde edilmiştir. Elde edilen verilerle öncelikle tanımlayıcı istatistiksel analizler yapılmış ve sonrasında araştırmada kullanılan ölçeklerin geçerlik ve güvenirlikleri test edilmiştir. Değişkenler arasındaki ilişkinin tespitine yönelik olarak korelasyon analizi yapılmıştır. Araştırma hipotezlerini test etmek için "process macro" kullanılmıştır. Çalışmanın bulguları; marka imajının satın alma niyetini anlamlı ve pozitif yönde etkilediğini ve müşteri tatmininin bu ilişkide tam aracı rolü olduğunu göstermiştir. Çalışmanın bulgularının satın alma niyetine yönelik literatürü genişleteceği, akıllı telefon sektöründe faaliyet gösteren firmaların da ilgisini çekeceği değerlendirilmektedir.

\section{The Mediating Role of Customer Satisfaction in the Effect of Brand Image on Purchase Intention: A Study on the University Students}

\begin{abstract}
In the global world smart phone brands become different by using their functional features with the effect of technological developments. The customers, on the other hand, choose brands that they find close to them according to their purchase intention. Previous studies in order to explain the purchasing intention of the customers have mostly been conducted on psychological, demographic, and perceptual factors. Since the customers consider the goods and services, they intend to purchase over the brand image, it is important for the firms to maintain a customer satisfaction-based relationship. The aim of this study is to examine the effect of brand image on purchase intention through the role of the mediating variable of customer satisfaction for university students using smart phones. In this research, survey data were obtained from 352 students selected from a foundation university in Istanbul with the convenient sampling method. First, descriptive statistical analyzes were made with the data obtained, then the validity and reliability of the scales used in the study were tested. Correlation analysis was conducted to determine the relationship between variables. In order to test the research hypotheses, process macro was used. The results of the analysis showed that brand image significantly and positively affects purchase intention and customer satisfaction has a full mediating role in this relationship. It is considered that the research findings will expand the literature on purchase intention and attract the attention of firms operating in the smart phone industry.
\end{abstract}

Anahtar Sözcükler: Satın Alma Niyeti, Marka İmajı, Müşteri Tatmini, Akılıı Telefon Kullanımı

JEL: M30, M31, M37

$\begin{array}{ll}\text { Geliş } & : 30 \text { Aralık } 2020 \\ \text { Düzeltme } & : 01 \text { Mart } 2021 \\ \text { Kabul } & : 31 \text { Mart } 2021 \\ & \\ \text { Tür } & \text { : Araştırma }\end{array}$

Keywords: Purchase Intention, Brand Image, Customer Satisfaction, Smart Phone Usage

JEL: M30, M31, M37

$\begin{array}{ll}\text { Received } & : 30 \text { December } 2020 \\ \text { Revised } & : 01 \text { March } 2021 \\ \text { Accepted } & : 31 \text { March } 2021 \\ \text { Type } & : \text { Research }\end{array}$




\section{Giriş}

Yirmi birinci yüzyılda kırsal alana oranla şehirlerde yaşayan nüfusun giderek artması gerek iletişim gerekse bilişim sektörlerindeki gelişmeler, müşterilerin eğitim seviyelerindeki yükselme ve genç nüfus nedeniyle müşterilerin cep telefonu kullanımı ciddi oranda artmıştır. Özellikle müşteriler açısından pazara sunulan akıllı telefonlar ise kendilerinin gündelik yaşamları ile iş hayatlarını kolaylaştıracak birçok uygulama sunmaktadır (Kalyoncuoğlu ve Faiz, 2017: 185). Türk Sanayicileri ve İş İnsanları Derneği (TüsiAD), Türkiye'de yetişkin müşterilerin yaklaşık \%98'inin mobil telefona sahip olduğunu, bu müşterilerin \%77'sinin akıllı telefon kullandığını, kullanılan akıllı telefonların oldukça yeni olduğunu ve sık değiştirildiğini 2019 yılında raporlamıştır. Aynı raporda genellikle genç nüfus olarak nitelendirilebilecek 18-34 yaş grubunun, 35-50 yaş grubu ile kıyaslandığında akılı telefonlarını bilgisayara göre daha fazla tercih ettiği belirtilmektedir (Türkiye Bilişim Sanayicileri Derneği, 2019: 11).

Müşterilere mobil iletişimin yanı sıra çok sayıda fayda sunan akıllı telefon markaları çetin bir rekabetin içindedir. Global dünyada teknolojik gelişmelerin etkisiyle sürekli değişim ve gelişimlerin yaşandığı söz konusu pazarda markalar da işlevsel özellikleri temelinde farklılaşmaya çalışmaktadır. Müşteriler ise satın alma niyetleri temelinde kendilerine yakın buldukları markaları seçmektedirler (Sağlam ve Sağlam, 2016: 35). Buna göre günümüzde işletmeler, marka yaratma ve geliştirme yatırımlarını önemli ölçüde artırmakta ve bu şekilde markalarının yaratılmasını gerçekleştirerek, oluşturulan marka imajı ile hedef kitlelerini meydana getiren müşterilerini markaları ile ilişkili duruma getirmektedirler. Söz konusu bu durum, müşterilerin satın alma niyetinin öncül unsurlarından birisi olarak belirtilen marka imajının etkisinin ölçülmesinin önemi ve gerekliliğini ortaya koymaktadır (Jalilvand ve Samiei, 2012).

Marka imajı yalnızca hizmet kalitesi, ürün veya fiyata odaklanan bir unsur olmaktansa, sosyal statüyü gösteren, diğer markalardan ayrımlanmış, psikolojik ve fizyolojik faydayı sağlayan bir kavramdır (Erdil, 2015: 198). Bu yüzden, müşteriler satın alma niyetinde oldukları ürünleri marka imajı üzerinden ele aldıklarından, işletmeler açısından müşteri tatmini esaslı ilişkiyi sürdürme önem kazanmaktadır (Yang, Yang, Chang ve Chien, 2017: 2286). Bu kapsamda, işletmeler açısından rekabet avantajı elde edebilmek için ürünlerini satın alan ve kullanan müşteriler ile müşteri odaklı faaliyetler kapsamında, onların beklenti ve taleplerini anlama, müşterilerin tatminini sağlama ve müşteriler ile iyi ilişkiler oluşturma önem atfedilen bir başka husustur (Hugos, 2011: 24).

Bu nedenle söz konusu çalışmada, üniversite öğrencilerinin akıllı telefon kullanımı özelinde, marka imajı değişkeninin satın alma niyeti üzerindeki etkisinin, müşteri tatmininin aracı değişken rolü üzerinden analiz edilmesi amaçlanmıştır. Literatürde ilgili değişkenlerle alakalı yapılan çalışmalar incelendiğinde, marka imajının satın alma niyeti üzerindeki etkisinin incelendiği çeşitli çalışmaların (Lin, 2013; Çakır, 2013; Mohammadzadeh, 2015; Nagar ve Rana, 2015; Karakaşoğlu ve Arslan, 2016; Rehman ve İshaq, 2017; Raza, Frooghi, Rani ve Qureshi, 2018; Onurlubaş, 2018; Agharzayev, 2019; Onurlubaş ve Altunışık, 2019) bulunduğu görülmektedir. Söz konusu bağımsız değiş̧kenler arasındaki ilişkinin sorgulanmasında, birtakım kavramların aracı değişken rolünün incelendiği görülmüş olup, cep telefonu kullanımı bağlamında müşteri tatmininin, bu iki değişkene yönelik ilişki çerçevesinde aracılık etkisinin ölçüldüğü yeterli çalışmanın bulunmadığı tespit edilmiştir. Bu kapsamda, sektörel paydaşlar olarak işletmeler ve müşteriler açısından, satın alma niyeti üzerindeki marka imajının direkt etkisi ile müşteri tatmininin aracı değişken rolü etkisiyle ampirik bir araştırma kapsamında gerçekleştiriliyor olmasının, pazarlama alanında Türkçe yazına katkı sağlayacağı değerlendirilmektedir. Buna göre çalışmanın geri kalanı şu şekilde yapılandırılmıştır. İkinci bölümde araştırmanın konusunu oluşturan kavramlar ve alan yazınında bulunan çalışmalarla ilgili kavramsal çerçeve ortaya koyulmuş ve araştırma modeline dayanarak hipotezler oluşturulmuştur. Üçüncü bölümde araştırma yöntemine ilişkin örneklem ve verilerin toplanması ile araştırmada kullanılan ölçekler açıklanmıştır. Dördüncü bölümde araştırma modeline ilişkin verilerin analizi ile elde edilen bulgular ifade edilmiş ve beşinci bölümde ise, söz konusu bulguların kavramsal çerçeve ile ilişkilendirilerek değerlendirilmesine ve sektör paydaşlarına önerilerde bulunulmasına yer verilmiştir. 


\section{Literatür ve Hipotez Geliştirme}

\subsection{Marka İmajı ve Satın Alma Niyeti}

Marka imajı, müşterinin marka ile ilgili düşünme şekli ve bir markayı düşündüğünde markanın oluşturduğu hisler, tutumlar olarak tanımlanmaktadır (Arslan ve Altuna, 2010: 172). Başka bir tanıma göre ise, anlamlı çağrışımların çeşitli iletişimler neticesinde müşteri zihninde meydana getirdiği algılamalardır (Can, 2007: 231). Müşteride markaya yönelik oluşan bu hisler ve tutumlar, sübjektif algılama imajları biçimindedir ve tüm bu imajlar bütünsel ve karmaşık marka imajını oluşturmaktadır. Bu nedenle müşterinin tutumları her zaman bir markaya veya ürüne yönlendirilmekte ancak daha önce söz konusu marka ile ilgili sahip olunan bir bilgi, deneyim veya etkileşim varsa marka imajı olarak ortaya çıkmaktadır (Nagar ve Rana, 2015: 64).

Müşterinin, bir markayı satın alma çabası oluşturmaya yönelik bilinçli planı, satın alma niyetini tanımlamaktadır (Spears ve Singh, 2004: 56). Satın alma niyetindeki müşteri, pazara bir sonraki ziyaretini ne zaman gerçekleştirse, aynı ürünü alma yönünde gizlenmiş bir girişim taşır (Tariq, Nawaz, Nawaz ve Butt, 2013: 341). Bu noktada müşteriler, markanın pozitif yöndeki imajının, müşteri değer algısının artmasına etkisi olduğu için muhtemelen pozitif marka imajına sahip bilinen marka ürünlerini seçmektedirler (Romaniuk ve Sharp, 2003: 219; Aghekyan, Forsythe, Kwon ve Chattaraman, 2012: 325). Böylece müşterinin marka ile ilgili duygusal cevabı, alternatif teklifler arasında farklılaşmaya yol açmakta (Alwi, 2009: 2), marka imajı yükseldikçe, satın alma niyeti de artmaktadır. İşletmelerin kârlarını mümkün olduğu ölçüde büyütmek amacıyla spesifik ürün satışlarını artırma isteği bulunduğundan, marka imajının satın alma niyeti üzerindeki etkisi, satın alma niyetinin müşteriyi elde tutma yönünden etkisi konusunda önem ifade etmektedir. (Tariq vd., 2013: 341). Literatürde yapılan incelemede, çeşitli çalışmalarda elde edilen bulgulara göre, marka imajının satın alma niyeti üzerinde anlamlı bir etkiye sahip olduğu görülmüştür. Bu kapsamda Lin (2013), Çakır (2013), Mohammadzadeh (2015), Nagar ve Rana (2015), Karakaşoğlu ve Arslan (2016), Rehman ve ìshaq (2017), Raza vd. (2018), Onurlubaş (2018), Agharzayev (2019), Onurlubaş ve Altunışık (2019) tarafından yapılan çalışmalarda, marka imajının satın alma niyeti üzerinde anlamlı bir etkiye sahip olduğu tespit edilmiştir.

Mevcut literatür doğrultusunda test edilmek üzere aşağıdaki hipotez geliştirilmiştir:

$\boldsymbol{H}_{1}$ : Marka imajı, satın alma niyetini anlamlı ve pozitif yönde etkiler.

\subsection{Marka İmajı ve Müşteri Tatmini}

Müşteri tatmini, müşterinin herhangi bir ürün ve hizmet ile ilgili zihninde oluşan algılarındaki beklentileri ile ürün veya hizmeti tecrübe etmeyi ve kullanmayı müteakip elde ettiği deneyim arasındaki farklılıktır (Burucuoğlu, 2011: 14). Söz konusu bu farklılık neticesinde, işletmeden memnun ayrılan müşteriler, memnun olmayanlara göre aynı işletmeyi tercih etme noktasında daha yüksek seviyede ürün ve hizmet satın alma yöneliminde bulunmaktadır. Bu kapsamda işletmeler, müşterilerinin tatminini sağlayarak, onlara daha fazla ürün ve hizmet satmanın yanında onlar ile uzun süreli ilişkiler kurmaktadırlar (Uludağ, Faiz ve Çatı, 2018: 576).

İşletmeler, sahip oldukları markalar ile ilgili güçlü ve olumlu bir imaj oluşturmaya çalışmaktadır. Bu şekilde, müşterinin ürün veya hizmetten algılayacağı riski azaltmakta ve güven duygusu oluşturarak, satın almanın tekrarlanmasını sağlamaktadır (Stan, Caemmerer ve Cattan-Jallet, 2013: 1542). Diğer bir ifade ile marka imajı yüksek olan işletmeler, müşterilerinin beklentilerini karşılayarak, onların işletmeden memnun bir şekilde ayrılmalarını ve işletmenin müşterisi olarak kalmalarını gerçekleştirmektedir (Uludağ vd., 2018: 576). Bu kapsamda, konuyla ilgili literatür incelendiğinde, marka imajının müşteri tatmini üzerinde anlamlı bir etkiye sahip olduğu belirlenmiştir (Hsiung, 2011; Eren ve Eker, 2012; Lahap, Ramli, Said, Radzi ve Zain, 2016; Sulibhavi ve Shivashankar, 2017; Hosseini ve Behboudi, 2017; Uludağ vd., 2018; Mohammed ve Rashid, 2018; Natalia ve Syevillia, 2018).

Mevcut literatür doğrultusunda test edilmek üzere aşağıdaki hipotez geliştirilmiştir:

$\boldsymbol{H}_{2}$ : Marka imajı, müşteri tatminini anlamlı ve pozitif yönde etkiler. 


\subsection{Müşteri Tatmininin Aracı Rolü}

İçinde bulunulan dönemde, küresel rekabetin etkisiyle işletmeler açısından müşterinin değeri ve önemi ön plana çıkmaktadır. Buna göre üretilen hizmet veya ürünlerin, müşterilerin beklentilerini karşılaması yanında müşterileri memnun etme, elde tutma gibi stratejiler geliştirme işletmeler yönünden gereklilik oluşturmaktadır (Çalışır, 2015: 163). Müşteri tatmininin sağlanarak sürdürülmesi, işletmelerin ürün veya hizmetlerinin satın alınması ile tüketimini etkilemektedir. Bu durum, işletmelerin hayatta kalma süreleri açısından önem arz etmektedir (Eskiler ve Altunışık, 2015: 486).

Literatür incelendiğinde, müşteri tatmini kavramının aracı değişken olarak kullanıldığı çok sayıda çalışma bulunmaktadır. Bu kapsamda, Srivastava ve Sharma (2013), Saeidi, Sofian, Saeidi, Saeidi ve Saaeidi (2015), Hussain (2016), Keshavarz ve Jamshidi (2018), Myo, Khalifa ve Aye (2019), Aburayyaa, Marzouqib, Alawadhic, Abdoulid ve Taryam (2020) gerçekleştirdikleri çalışmalarda, söz konusu kavramı, farklı değişkenler arasındaki aracılık etkisinin ölçülmesi anlamında kullanmışlardır. Bunun yanında, müşterilerin satın alma niyetlerini etkileyen hususlar açısından ise, farklı birtakım kavramların aracı değişken rolü de araştırılmıştır. Bu kapsamda, Nagar ve Rana (2015) algılanan faydanın, Rehman ve Ishaq (2017) mağaza imajının, Qomariah ve Prabawani (2019) algılanan ürün fiyatı ve kalitenin, satın alma niyeti üzerindeki aracı rolünü test etmişlerdir. Bu çalışmada ise, küresel rekabet ortamında bulunan işletmelerin faaliyetlerini sürdürebilmesi açısından satın alma niyetine muhtemel etkisi nedeniyle müşteri tatmini kavramı aracı değişken olarak kullanılmıştır.

Mevcut literatür doğrultusunda test edilmek üzere aşağıdaki hipotezler geliştirilmiştir:

$H_{3}$ : Müssteri tatmini satın alma niyetini anlamlı ve pozitif yönde etkiler.

$\boldsymbol{H}_{4}:$ Marka imajının, satın alma niyetine etkisinde müşteri tatmininin aracı rolü vardır.

\section{Metot}

\section{1. Örneklem ve Verilerin Toplanması}

Araştırma verileri İstanbul'da bulunan ve toplam öğrenci sayısı 4.315 olan bir vakıf üniversitesindeki öğrencilerden elde edilmiştir. Buna göre araştırmanın anakütlesi söz konusu vakıf üniversitesi öğrencileridir. Tüm evrene ulaşmanın maliyet ve zaman açısından mümkün olmaması nedeniyle İstanbul'da merkezi konumda bulunan vakıf üniversitesinde araştırma yapılmıştır. Araştırmanın örneklem büyüklüğü olarak, Barlett, Körtlik ve Higgins (2001) tarafından önerilen formül aşağıda belirtildiği şekilde kullanılmış, \%95 güven aralığı ve \%5 örneklem hatası ile 352 sayısına ulaşılmıştır.

$$
\begin{aligned}
& \mathrm{n}=\frac{\mathrm{N} * t^{2} \mathrm{p} * \mathrm{q}}{(\mathrm{N}-1) d^{2}+t^{2} * \mathrm{p} * \mathrm{q}} \\
& \mathrm{n}=\frac{4315 * 1,96^{2} * 0,50 * 0,50}{4314 * 0,05^{2}+1,96^{2} * 0,50 * 0,50}=352
\end{aligned}
$$

Araştırmacı tarafından öğrencilerin yoğun olarak bulunduğu kafeterya, dinlenme tesisleri ve spor alanlarına gidilmiş ve yerinde kapalı zarflarda anketler kolayda örneklem metodu uygulanarak öğrencilere dağıtılmıştır. Araştırma için 500 anket hazırlanmıştır. Yapılan çalışma neticesinde 410 ankette geri dönüş sağlanmıştır. Elde edilen anketler araştırmacı tarafından incelenmiş ve eksik doldurulan 31 anket araştırmaya dâhil edilmemiştir. Araştırmaya dâhil edilen anketler aykırı değerlere göre incelenmiş ve 27 anket verisi araştırmadan çıkarılmıştır. Böylelikle araştırma için 352 geçerli anket verisi elde edilmiştir. Araştırma 04 Kasım - 12 Kasım 2019 tarihleri arasında yüz yüze yapılmış ve bir anketin doldurulma süresi ortalama 5 dakika olarak hesaplanmıştır. Katılımcıların 183'ü erkek, 169'u kadındır, 65 katılımcı evli iken 287 katıımcı bekârdır. 


\section{2. Ölçekler}

Araştırma kapsamında hazırlanan ankette yer alan ifadeler beşli Likert tipindedir. Her bir ifade 1=Kesinlikle Katılmıyorum, 2=Katılmıyorum, 3=Kararsızım, 4=Katılıyorum ve 5=Kesinlikle Katılıyorum'u ifade etmektedir. Katılımcıların ölçeklere verdikleri puanlar arttıkça ölçekte belirtilen tutum veya davranışa yönelik algıları da artmaktadır.

Marka Imajı: Araştırmanın bağımsız değişkeni olan marka imajına yönelik olarak Kim ve Kim (2005) tarafından geliştirilen ölçek kullanılmıştır. Kayaman ve Araslı (2007) tarafından Türkçe'ye uyarlanan ölçekte sekiz ifade bulunmaktadır. Araştırmada ölçeğin güvenirlik Cronbach's Alpha iç tutarlılık kat sayısı 0,916 olarak ölçülmüştür.

Müşteri Tatmini: Katılımcılarda müşteri tatmininin tespit edilmesine yönelik olarak Han ve Ryu (2012) tarafından geliştirilen ölçek kullanılmıştır. Bilgin (2017) tarafından Türkçe'ye uyarlanan ölçekte üç ifade bulunmaktadır. Araştırmada ölçeğin güvenirlik Cronbach's Alpha iç tutarlııı kat sayısı 0,850 olarak ölçülmüştür.

Satın Alma Niyeti: Katılımcılarda satın alma niyetlerinin tespit edilmesine yönelik olarak Nguyen ve Leblanc (2001) tarafından geliştirilen ölçek kullanılmıştır. Bu ölçek Marangoz (2006) tarafından Türkçeye uyarlanmıştır. Ölçekte üç ifade bulunmaktadır. Araştırmada ölçeğin güvenirlik Cronbach's Alpha iç tutarlılık kat sayısı 0,876 olarak ölçülmüştür.

\section{Bulgular}

Araştırma hipotezlerini test etmeden önce AMOS-18 programı yardımıyla ölçeklerin yapısal geçerlilikleri ve güvenirlikleri kontrol edilmiştir. Yapılan analiz sonuçları Tablo 1'de gösterilmiştir.

Tablo 1. Doğrulayıcı Faktör Analizi Sonuçları

\begin{tabular}{lccccc}
\hline & Madde & Faktör Yükü & AVE & Cr & $\boldsymbol{\alpha}$ \\
\hline MI1 & 0,797 & & & \\
Marka İmajı & MI2 & 0,871 & & & \\
& MI3 & 0,798 & & & \\
& MI4 & 0,760 & & & \\
& MI6 & 0,784 & 0,534 & 0,899 & 0,916 \\
& MI7 & 0,639 & & & \\
Müşteri Tatmini & MI8 & 0,744 & & & \\
& MT1 & 0,671 & & & \\
& MT2 & 0,799 & & & \\
\multirow{3}{*}{ Satın Alma Niyeti } & MT3 & 0,905 & 0,663 & 0,854 & 0,850 \\
& SAN1 & 0,730 & & & \\
& SAN2 & 0,874 & & & \\
& SAN3 & 0,832 & 0,705 & 0,877 & 0,876 \\
\hline
\end{tabular}

AVE: Çıkarılan Ortalama Varyans, Cr: Birleşik Güvenirlik, $\alpha$ : Cronbach's Alpha

Yapılan analizler sonucunda değişkenlere ait faktör yüklerinin 0,639 ile 0,905 arasında olduğu tespit edilmiştir. Ayrıca AVE değerlerinin 0,5'in üzerinde olması ölçeklerin yakınsak geçerliliğe sahip olduğunu göstermektedir (Nunnally ve Burnstein, 1994). Birleşik güvenirlik ve Cronbach's Alpha katsayılarının 0,7'nin üzerinde olması araştırmada kullanılan ölçeklerin iç tutarlılıklarının olduğunu ve güvenilir olduğunu göstermektedir (Sürücü ve Maslakçı, 2020: 2703). Bundan sonra araştırma modelinin uyum indeksleri hesaplanmıştır (CMIN= 168.768, Df= 70, CMIN/Df= 2.411, GFI=0,935, NFI=0,952, TLI=0,962, CFI=0,971, RMSEA $=0,53$ ). Elde edilen değerler araştırma modelinin iyi uyum indekslerine sahip olduğunu göstermiştir (Meydan ve Şeşen, 2015). 
Ölçeklerin geçerli ve güvenilir olduğunun tespit edilmesinden sonra korelasyon analizleri yapılmıştır. Korelasyon analizinde hangi katsayının kullanılacağının tespit edilmesi için verilerin dağılımı kontrol edilmiştir. Yapılan analizlerde çarpıklık ve basıklık değerlerinin $+1,5$ ile $-1,5$ arasında bulunduğu ve verilerin normal dağılıma sahip olduğu tespit edilmiştir (Hair, Hult, Ringle ve Sarstedt, 2014). Bu nedenle korelasyon analizinde Pearson katsayısı dikkate alınmıştır. Elde edilen bulgular Tablo 2'de sunulmuştur.

Tablo 2. Korelasyon Sonuçları

\begin{tabular}{lccccc}
\hline Değişkenler & Ort. & Sd & $\mathbf{1 .}$ & $\mathbf{2 .}$ & $\mathbf{3 .}$ \\
\hline 1. Marka İmajı & 3,52 & 1,02 & 1 & & \\
2. Müşteri Tatmini & 3,79 & 1,01 & $0,681^{* *}$ & 1 & \\
3. Satın Alma Niyeti & 3,47 & 1,13 & $0,805^{* *}$ & $0,585^{* *}$ & 1 \\
\hline $\mathrm{N}=352,{ }^{* *} \mathrm{p}<0,01$ & & & & &
\end{tabular}

Tablo 2' de görüldüğü üzere marka imajının, müşteri tatmini $(r=0,681, p<0,01)$ ve satın alma niyeti $(r=0,805, \mathrm{p}<0,01)$ ile pozitif yönlü bir korelasyonu bulunmaktadır. Ayrıca müşteri tatmini ile satın alma niyeti arasında da pozitif yönlü bir korelasyon bulunmaktadır $(r=0,585, p<0,01)$. Korelasyon analizi sonuçları, marka imajının müşteri tatmini ile orta, satın alma niyeti ile de güçlü bir ilişkisi olduğunu göstermektedir (Cohen, 1988).

Araştırma hipotezlerini test etmek için Hayes (2013) tarafından önerilen Process Macro kullanılmıştır. Process Macro, Baron ve Kenny (1986)'nin nedensel adımlar yöntemine yapılan eleştiriler doğrultusunda geliştirilen ve nedensel adımlar yönteminin potansiyel eksiklerini ortadan kaldıran bir yöntemdir (Hayes, 2017). Bu nedenle araştırma hipotezlerini test etmek için Process Macro kullanılmıştır. Analiz sonuçları Tablo 3'te gösterilmiştir.

Tablo 3. Bootstrap Sonuçları

\begin{tabular}{clcccc}
\hline Hipotez & Regresyon Yolu & $\begin{array}{c}\text { Etki } \\
\text { Katsayıs }\end{array}$ & SH & LLCl & ULCI \\
\hline $\mathrm{H} 1$ & $\mathrm{MI} \rightarrow$ SAN & 0,267 & 0,536 & 0,1621 & 0,3727 \\
$\mathrm{H} 2$ & $\mathrm{MI} \rightarrow \mathrm{MT}$ & 0,693 & 0,454 & 0,6035 & 0,7819 \\
$\mathrm{H} 3$ & $\mathrm{MT} \rightarrow$ SAN & 0,563 & 0,489 & 0,4670 & 0,6593 \\
$\mathrm{H} 4$ & Dolaylı Etki $(\mathrm{MI} \rightarrow \mathrm{MT} \rightarrow$ SAN & 0,390 & 0,526 & 0,2892 & 0,4958 \\
\hline
\end{tabular}

MI: Marka İmajı, MM: Müşteri Tatmini, SAN: Satın Alma Niyeti

Tablo 3'teki bulgular; marka imajının satın alma niyetini $(\beta=0,267,95 \% \mathrm{Cl}=[0,1621,0,3727], \mathrm{t}=4,9933$, $p<0,05)$ ve müşteri tatminini $(\beta=0,693,95 \% \mathrm{Cl}=[0,6035,0,7819], t=15,2741, p<0,05)$ anlamlı ve pozitif yönde etkilediğini göstermektedir. Ayrıca müşteri tatmini satın alma davranışını anlamlı ve pozitif yönde etkilemektedir $(\beta=0,563,95 \% \mathrm{Cl}=[0,4670,0,6593], t=11,5182, p<0,05)$. Bu bulgular doğrultusunda $\mathrm{H}_{1}, \mathrm{H}_{2}$ ve $\mathrm{H}_{3}$ desteklenmiştir. Araştırmanın son hipotezi olan, marka imajının satın alma niyetine etkisinde müşteri tatmininin aracı rolünün tespitine yönelik olarak dolaylı etki kontrol edilmiş ve müşteri tatmininin aracı rolü olduğu tespit edilmiştir $(\beta=0,390, \mathrm{SH}=0,0529,95 \% \mathrm{BCA} \mathrm{Cl}=[0,2892,0,4958])$. Bu doğrultuda $\mathrm{H}_{4}$ de desteklenmiştir.

\section{Tartışma ve Sonuç}

Literatür incelendiğinde, satın alma niyetini etkileyen faktörlerin belirlenmesine yönelik güncel çalışmalar yapıldığı görülmektedir (Younus, Rasheed ve Zia, 2015; Mirabi, Akbariyeh ve Tahmasebifard, 2015; Alalwan, 2018; Pena-Garcia, Gil-Saura, Rodriguez-Orejuela ve Siqueira-Junior, 2020). Bu çalışmada, bağımsız 
değişken olarak marka imajının ve aracı değişken olarak müşteri tatmininin, satın alma niyeti üzerindeki güçlü etkisi ortaya koyulmuştur. Böylece müşterilerin satın alma niyetlerinin belirlenmesi kapsamındaki bu araştırma ile literatüre katkı sağlanmakta ve işletme yöneticileri açısından da öneriler ortaya koyulmaktadır. Buna göre, araştırma kapsamındaki ana bulgular aşağıdaki gibidir.

Araştırmada marka imajının, satın alma niyetini anlamlı ve pozitif yönde etkilediği tespit edilmiştir. Müşteriler, satın alma davranışından önce intiyaçları doğrultusunda cep telefonu pazarında araştırma gerçekleştirdiklerinde, herhangi bir markaya yönelik hislerinin, tutumlarının, algılamalarının etkisinde kalmaktadırlar. Bu sübjektif algılamaların etkisiyle bir markaya yönlenen müşteriler, söz konusu marka ile ilgili daha önceki bilgi ve deneyimlerini nazara alarak tutumlarını göstermektedirler. Bu şekilde marka imajı doğrultusunda ihtiyaçlarını gidermeye ilişkin satın alma davranışını göstermektedirler. Marka imajı temelinde oluşan güven ortamı, müşteri ile işletme arasındaki ilişkiyi etkilemektedir. Araştırma kapsamında elde edilen bu bulgu, önceki araştırmaların bulgularıyla da örtüşmektedir (Lin, 2013; Çakır, 2013; Mohammadzadeh, 2015; Nagar ve Rana, 2015; Karakaşoğlu ve Arslan, 2016; Rehman ve İshaq, 2017; Raza vd., 2018; Onurlubaş, 2018; Agharzayev, 2019; Onurlubaş ve Altunışık, 2019).

Marka imajının satın alma niyetine etkisinin ölçülmesinde, müşteri tatmininin aracı rolünün bulunduğunun tespit edilmesi gerek araştırmacılar gerekse işletme yöneticileri açısından önemlidir. Kotler ve Armstrong (2012: 7) tarafından ifade edildiği gibi işletme yöneticilerinin, müşterilerden karşıı̆ını alabilmeleri için müşteri değeri oluşturma ve müşteri tatmini sağlama konusunda ehil olmaları gerekmektedir. Bu şekilde müşteri değerini odak noktasına alarak faaliyetlerini yürütmekte olan işletmeler, müşterilerinin beklentilerini karşılamakta, onları memnun ederek elde tutmaktadırlar (Çalışır, 2015: 163). Müşteri tatmininin önemi, müşterilerin satın alma niyetlerini büyük ölçüde etkilemesinden ileri gelmektedir. Müşteri tatmini gerçekleştirilenler, yüksek ihtimalle yaşadıkları tecrübeleri etraflarındaki diğer kişiler ile paylaşmaktadırlar (Mohsan, Nawaz, Khan, Shaukat ve Aslam, 2011: 263). Müşteri tatmini temelinde, işletmelerin ürün veya hizmetlerinin satın alınması neticesinde küresel rekabet ortamında işletmelerin varlıklarını sürdürebilmesi mümkün olmaktadır (Eskiler ve Altunışık, 2015: 486). Bu bilgiler ışığında, müşteri tatmininin satın alma niyeti üzerinde aracılık etkisi bulunmaktadır. Araştırma kapsamında, marka imajının satın alma niyetine etkisinde müşteri tatmininin aracılık rolü belirlenmiştir.

Araştırma bulguları değerlendirilirken bazı sınırlılıklar dikkate alınmalıdır. Öncelikle araştırmanın genç yetişkinler üzerinde yapılmış olması ve örneklem grubunun vakıf üniversitesinin öğrenicilerinin oluşturulması araştırma bulgularının genelleştirilebilmesi için yetersizdir. Ayrıca araştırma verilerinin $04-12$ Kasım 2019 tarihleri arasında toplanması da önemli bir sınırlııktır. Illeride yapılacak araştırmalarda yakın tarihli verilerin kullanılması ve örneklemin genişletilmesi bu araştırmanın sınırlıklarını ortadan kaldırabilecektir.

\section{Beyan ve Açıklamalar (Declarations and Disclosures)}

Yazarların Etik Sorumlulukları (Ethical Responsibilities of Authors): Bu çalışmanın yazarı, araştırma ve yayın etiği ilkelerine uyduğunu kabul etmektedir.

Çıkar Çatışması (Conflicts of Interest): Yazar tarafından herhangi bir çıkar çatışması beyan edilmemiştir.

Finansal Destek (Funding): Yazar, çalışmanın hazırlanması ve/veya yayınlanması sürecinde herhangi bir finansal destek almamıştır.

Yazar Katkı Oranı (Author Contributions): Yazar; kavramlaştırma ve çalışma dizaynı, verilerin toplanması, verilerin analizi ve sonuçların yorumlanması, çalışmanın ilk/taslak halinin yazılması, çalışmanın gözden geçirilmesi ve düzenlenmesi/düzeltilmesi aşamalarından tek başına sorumlu olduğunu beyan etmektedir.

intihal Denetimi (Plagiarism Checking): Bu çalışma, intihal tarama programı kullanılarak intihal taramasından geçirilmiştir. 


\section{Kaynaklar}

Aburayyaa, A., Marzouqib, A. A., Alawadhic, D., Abdoulid, F., \& Taryam, M. (2020). An empirical investigation of the effect of employees' customer orientation on customer loyalty through the mediating role of customer satisfaction and service quality. Management Science Letters, 10(10), 2147-2158.

Agharzayev, E. (2019). Mağaza imajı ve özel marka imajı ile önceki deneyimin özel markalarda algılanan risk ve satın alma niyetine etkisi: Türkiye - Azerbaycan kıyaslaması. Marmara Üniversitesi Sosyal Bilimler Enstitüsü, Yüksek Lisans Tezi, İstanbul.

Aghekyan, M., Forsythe, S., Kwon, W. S., \& Chattaraman, V. (2012). The role of product brand image and online store image on perceived risks and online purchase intentions for apparel. Journal of Retailing and Consumer Services, $19,325-331$.

Alalwan, A. A. (2018). Investigating the impact of social media advertising features on customer purchase intention. International Journal of Information Management, 42, 65-77.

Alwi, S. F. S. (2009). Online corporate brand images and consumer loyalty. International Journal of Business and Society, 10(2), 1-19.

Arslan, F. M., \& Altuna, O. K. (2010). The effect of brand extensions on product brand image. Journal of Product \& Brand Management, 19(3), 170-180.

Barlett, J. E., Kotrlik J. W., \& Higgins C. C. (2001). Organizational research: Determining appropriate sample size in survey research. Information Technology, Learning, and Performance Journal, 19(1), 43-50.

Baron, R. M., \& Kenny, D. A. (1986). The moderator-mediator variable distinction in social psychological research: Conceptual, strategic, and statistical considerations. Journal of Personality and Social Psychology, 51(6), 11731182.

Bilgin, Y. (2017). Restoran işletmelerinde hizmet kalitesi, müşteri memnuniyeti ve müşteri sadakatinin ağızdan ağıza pazarlamaya etkisi. Iş̧letme Araştırmaları Dergisi, 9(4), 33-62.

Burucuoğlu, M. (2011). Müşteri memnuniyeti ve sadakatini arttırmada müşteri şikayetleri yönetiminin etkinliği: Bir örnek olay incelemesi. Karamanoğlu Mehmet Bey Üniversitesi Sosyal Bilimler Enstitüsü, Yüksek Lisans Tezi, Karaman.

Can, E. (2007). Marka ve marka yapılandırma. Marmara Üniversitesi i.i.B.F. Dergisi, 22(1), 225-237.

Cohen, J. (1988), Statistical power analysis for the behavioral science. Hillsdale: Lawrence Erlbaum Associates.

Çakır, H. Ö. (2013). Ürün geri çağırma stratejilerinin marka imajı ve tüketicilerin satın alma niyetleri üzerindeki etkisi: Otomotiv sektörü üzerine bir uygulama. Erciyes Iletişim Dergisi, 3(2), 44-56.

Çalışır, G. (2015). Müşteri ilişkileri yönetiminin önemi ve etkisi üzerine bir çalışma: Eskişehir Sanayi Odası ATAP A.Ş. örneği. Gümüşhane Üniversitesi Sosyal Bilimler Enstitüsü Dergisi, 6(12), 159-184.

Erdil, T. S. (2015). Effects of customer brand perceptions on store image and purchase intention: An application in apparel clothing. Procedia-Social and Behavioral Sciences, 207(20), 196-205.

Eren, S. S., \& Eker, B. U. S. (2012). Kurumsal sosyal sorumluluk algısının marka imajı, algılanan değer, müşteri tatmini ve marka sadakatine etkisi üzerine bir saha araştırması: X markası örneği. Süleyman Demirel Üniversitesi Iktisadi ve idari Bilimler Fakültesi Dergisi, 17(2), 451-472.

Eskiler, E., \& Altunışık, R. (2015). Algılanan değer ve müşteri memnuniyetinin satın alma eğilimleri üzerine etkisi. III. Rekreasyon Araştırmaları Kongresi.

Hair, J., Hult, G. T. M., Ringle, C., \& Sarstedt, M. (2014). A primer on partial least squares structural equation modeling (PLS-SEM). CA: Thousands Oaks, Sage.

Han, H., \& Ryu, K. (2012). Key factors driving customers' word-of-mouth intentions in full-service restaurants: The moderating role of switching costs. Cornell Hospitality Quarterly, 53(2), 96-109.

Hayes, A. F. (2013). Introduction to mediation, moderation, and conditional process analysis: A regression-based approach. New York: Guilford Press

Hayes, A. F. (2017). Introduction to mediation, moderation, and conditional process analysis: A regression-based approach. New York: Guilford Press.

Hosseini, S. H., \& Behboudi, L. (2017). Brand trust and image: Effects on customer satisfaction. International Journal of Health Care Quality Assurance, 30(7), 580-590. 
Hsiung, L. C. (2011). A study on the relations between the brand image and customer satisfaction in catering business. African Journal of Business Management, 5(18), 7732-773.

Hugos, M. (2011). Essentials of supply chain management. New Jersey: John Wiley \& Sons, Inc.

Hussain, R. (2016). The mediating role of customer satisfaction: Evidence from the airline industry. Asia Pacific Journal of Marketing and Logistics, 28(2), 234-255.

İstanbul Valiliği (2020). Üniversite Şehri İstanbul. İçişleri Bakanlığı. http://www.istanbul.gov.tr/universite-sehri-istanbul (Erişim Tarihi: 10 Aralık 2020).

Jalilvand, R. M., \& Samiei, N. (2012). The effect of electronic word of mouth on brand image and purchase intention: An empirical study in the automobile industry in Iran. Marketing Intelligence \& Planning, 30(4), 460-476.

Kalyoncuoğlu, S., \& Faiz, E. (2017). Müşterilerin sadakat geliştirme eğilimlerini etkileyen faktörlerin belirlenmesi: Akıllı telefon kullanıcıları üzerinde bir araştırma. Gazi Üniversitesi İktisadi ve Idari Bilimler Fakültesi Dergisi, 19(1), 184210.

Karakaşoğlu, M., \& Arslan, M. G. (2016). Mağaza hizmet ortamının marka imajına ve satın alma niyetine etkisi: P\&B ve H\&M örneği. Marmara Üniversitesi Öneri Dergisi, 12(46), 223-243.

Kayaman, R., \& Arasli, H. (2007). Customer based brand equity: Evidence from the hotel industry. Managing Service Quality, 17, 92-109.

Keshavarz, Y., \& Jamshidi, D. (2018). Service quality evaluation and the mediating role of perceived value and customer satisfaction in customer loyalty. International Journal of Tourism Cities, 4(2), 220-244.

Kim, H. B., \& Kim, W. G. (2005). The relationship between brand equity and firms' performance in luxury hotels and chain restaurants. Tourism Management, 26(4), 549-560.

Kotler, P., \& Armstrong, G. (2012). Principles of marketing. England: Pearson Education Limited.

Lahap, J., Ramli, N. S., Said, N. M., Radzi, S. M., \& Zain, R. A. (2016). A study of brand image towards customer's satisfaction in the Malaysian hotel industry. Procedia - Social and Behavioral Sciences, 224, 149-157.

Lin, C. H. (2013). The effects of brand images on purchase intention in catering industry. Pakistan Journal of Statistics, 29(5), 745-754.

Marangoz, M. (2006). Tüketicilerin marka fonksiyonu algılamaları ile satın alma sonrası davranışları arasındaki ilişki. Dokuz Eylül Üniversitesi Iktisadi ve Idari Bilimler Fakültesi Dergisi, 21(2),107-128.

Meydan, C. H., \& Şeşen, H. (2015). Yapısal eşitlik modellemesi: AMOS uygulamaları (2.Baskı). Ankara: Detay Yayıncılık.

Mirabi, V., Akbariyeh, H., \& Tahmasebifard, H. (2015). A study of factors affecting on customers purchase intention. Journal of Multidisciplinary Engineering Science and Technology, 2(1), 267-273.

Mohammadzadeh, R. (2015). The effect of brand image and purchase intention on cosmetic products: Evidence from North Cyprus. Master of Arts in Marketing Management, Eastern Mediterranean University Gazimağusa, North Cyprus.

Mohammed, A., \& Rashid, B. (2018). A conceptual model of corporate social responsibility dimensions, brand image, and customer satisfaction in Malaysian hotel industry. Kasetsart Journal of Social Sciences, 39(2), 358-364.

Mohsan, F., Nawaz, M. M., Khan, M. S., Shaukat, Z., \& Aslam, N. (2011). Impact of customer satisfaction on customer loyalty and intentions to switch: Evidence from banking sector of Pakistan. International Journal of Business and Social Science, 2(16), 263-270.

Myo, Y. N., Khalifa, G. S. A., \& Aye, T. T. (2019). The impact of service quality on customer loyalty of Myanmar Hospitality Industry: The mediating role of customer satisfaction. International Journal of Management and Human Science, 3(3), 1-11.

Nagar, K., \& Rana, S. (2015). Examining linkages between brand image and purchase intention of green products: The moderating role of perceived benefits. FIIB Business Review, 4(2), 63-72.

Natalia, \& Syevillia, G. (2018). Local brand vs imported brand: An analysis of brand image on customer satisfaction and behavioural intention. Social Sciences \& Humanities, 26, 253-264.

Nguyen, N., \& Leblanc, G. (2001). Corporate image and corporate reputation in customers' retention decisions in services. Journal of Retailing and Consumer Services, 8(4), 227-236.

Nunnally, J. C., \& Bernstein, I. H. (1994). The theory of measurement error. In: Psychometric theory. (3rd Ed.). New York: McGraw-Hill. 
Onurlubaş, E. (2018). Marka değeri boyutlarının marka bağlılı̆ı ve satın alma niyeti üzerine etkisi: $X$ marka beyaz eşya kullanıcıları üzerine bir uygulama. Turkish Studies, Economics, Finance and Politics, 13(30), 273-302.

Onurlubaş, E., \& Altunışık, R. (2019). Tüketici etnosentrizmi ve marka imajının satın alma niyeti üzerindeki etkisi: Gıda tüketicileri üzerine bir uygulama. Uluslararası Toplum Araştırmaları Dergisi, 10(17), 1-31.

Pena-Garcia, N., Gil-Saura, I., Rodríguez-Orejuela, A., \& Siqueira-Junior, J. R. (2020). Purchase intention and purchase behavior online: A cross-cultural approach. Heliyon, 6(6), 1-11.

Qomariah, A., \& Prabawani, B. (2019). The effects of environmental knowledge, environmental concern, and green brand image on green purchase intention with perceived product price and quality as the moderating variable. IOP Conference Series: Earth and Environmental Science, 448, 1-12.

Raza, M., Frooghi, R., Rani, S. H. B., \& Qureshi, M. A. (2017). Impact of brand equity drivers on purchase intention: A moderating effect of entrepreneurial marketing. South Asian Journal of Management Sciences, 12(1), 69-92.

Rehman, H. I. U., \& Ishaq, Z. (2017). The impact of brand image on purchase intention: Moderating role of store image in Pakistan's retail sector. The IUP Journal of Brand Management, 14(3), 54-66.

Romaniuk, J., \& Sharp, B. (2003). Measuring brand perceptions: Testing quantity and quality. Journal of Targeting, Measurement and Analysis for Marketing, 11(3), 218-229.

Saeidi, S. P., Sofian, S., Saeidi, P., Saeidi, S. P., \& Saaeidi, S. A. (2015). How does corporate social responsibility contribute to firm financial performance? The mediating role of competitive advantage, reputation, and customer satisfaction. Journal of Business Research, 68(2), 341-350.

Sağlam, B. Ç., \& Sağlam, M. (2016). Marka güveni ve marka bağlılığının satın alma niyeti üzerine etkisi: Akıllı telefon pazarında bir araştırma. İşletme \& Sosyal Bilimler Araştırmaları Dergisi, 5(5), 34-43.

Spears, N., \& Singh, S. N. (2004). Measuring attitude toward the brand and purchase intentions. Journal of Current Issues and Research in Advertising, 26(2), 53-66.

Srivastava, K., \& Sharma, N. K. (2013). Service quality, corporate brand image, and switching behavior: The mediating role of customer satisfaction and repurchase intention. Services Marketing Quarterly, 34(4), 274-291

Stan, V., Caemmerer, B., \& Cattan-Jallet, R. (2013). Customer loyalty development: The role of switching costs. Journal of Applied Business Research, 29(5), 1541-1554.

Sulibhavi, B., \& Shivashankar, K. (2017). The impact of brand image on customer's loyalty towards private label brands: The mediating effect of satisfaction: Hublı-Dharwad Conglomerate city of Karnataka. International Journal of Marketing \& Financial Management, 5(8), 43-50.

Sürücü, L., \& Maslakçı, A. (2020). Validity and reliability in quantitative research. Business \& Management Studies: An International Journal, 8(3), 2694-2726.

Sürücü, L., Yeşilada, F., \& Maslakçı, A. (2020). Purchasing intention: A research on mobile phone usage by young adults. The Journal of Asian Finance, Economics and Business (JAFEB), 7(8), 353-360.

Tariq, M. I., Nawaz, M. R., Nawaz, M. M., \& Butt, H, A. (2013). Customer perceptions about branding and purchase intention: A study of FMCG in an emerging market. Journal of Basic and Applied Scientific Research, 3(2), 340347.

Türkiye Bilişim Sanayicileri Derneği (2019). E-Ticaretin gelişimi, sınırların aşılması ve yeni normlar. http://www.tubisad.org.tr/tr/images/pdf/dd-tusiad-eticaret-raporu-2019.pdf (Erişim Tarihi: 10 Aralık 2020).

Uludağ, G., Faiz, E., \& Çatı, K. (2018). Akıllı telefon pazarında marka imajının müşteri sadakati üzerindeki etkisinde müşteri memnuniyetinin aracılık rolü. İşletme Araştırmaları Dergisi, 10(4), 575-599.

Yang, K. F., Yang, H. W., Chang, W. Y., \& Chien, H. K. (2017). The effect of service quality among customer satisfaction, brand loyalty and brand image. International Conference on Industrial Engineering and Engineering Management, 2286-2290.

Younus, S., Rasheed, F., \& Zia, A. (2015). Identifying the Factors Affecting Customer Purchase Intention. Global Journal of Management and Business Research, 15(2), 1-7. 